\title{
INFLUENCE OF NITROGEN DIOXIDE AND ACETYLENE ON MARBLES, CERAMICS AND PIGMENTS
}

\author{
F. ROUBANI-KALANTZOPOULOU* \\ T. AGELAKOPOULOU \\ I. BASSIOTIS \\ S. MARGARITI \\ V. SIOKOS \\ E. METAXA
}

Received: 07/11/07

Accepted: 14/12/07

\author{
School of Chemical Engineering \\ National Technical University of Athens \\ 15780 Zografou, Athens, Greece
}

\begin{abstract}
The air pollution has a great impact on the social and economic aspects all over the world. Thus, the interaction of materials with the atmosphere has received increased attention nowadays. In order to estimate the impacts of air pollution on the solid surfaces a suitable scientific basis is developed and the well known Reversed Flow - Inverse Gas Chromatography, RF- IGC, is used. This dynamic experimental technique leads to very interesting experimental results through the determination of some important physicochemical quantities. The solids studied were Pentelic marble, white $\mathrm{TiO}_{2}$ pigment, ceramic and the gases were $\mathrm{NO}_{2}$ and $\mathrm{C}_{2} \mathrm{H}_{2}$. The synergistic effects between acetylene and nitrogen dioxide were also investigated. Through the curves obtained for each adsorption quantity determined versus time, one can easily and accurately conclude the result of the pollution impact on every solid mentioned above. The surface topography and the mechanism of deterioration can also be studied. All the above answer in detail to the questions of where, when and how the influence of gas pollutants on materials of cultural heritage takes place.
\end{abstract}

KEYWORDS: RF-IGC, $\mathrm{TiO}_{2}, \mathrm{C}_{2} \mathrm{H}_{2}, \mathrm{NO}_{2}$, Pentelic marble, ceramic, air pollution, local adsorption quantities.

\section{INTRODUCTION}

The interaction of materials with the atmosphere has received increased attention nowadays. Automobile emission is the major source of air pollution in many cities and countries. The major components are oxides of nitrogen and volatile organic compounds. Moreover, historical buildings and monuments, especially in Europe, decorated with works of art on their exterior surfaces, are suffering not only from the time and weather injuries but also from the fateful attack of air pollution (Metallo-Chiarra et al., 1995; Roubani-Kalantzopoulou et al., 2001). Another important problem arises from the coexistence of a second pollutant and the synergy of two pollutants or not (Kalantzopoulos et al., 1998; Siokos et al., 2002; Agelakopoulou et al., 2007).

In order to estimate the impacts of air pollution on the solid surfaces, a suitable scientific basis is required. It is well known that Inverse Gas Chromatography, IGC, is a promising meeting place of surface science and atmospheric chemistry (Katsanos et al., 2000; Charmas et al., 2000; Eiceman et al., 2000; Roubani-Kalantzopoulou 2004). In a previous publication (Arvatinopoulou et al., 1994), the use of denuder tubes with gas chromatographic instrumentation was described for measuring rate coefficients and equilibrium constants pertaining to corrosion phenomena caused by air pollutants on artistic objects. Moreover, further advances were achieved recently. As air pollution has a great impact on the social and economic aspects all over the world, in this work we shall stress the recent new aspect of 
Reversed Flow-Inverse Gas Chromatography, RF-IGC, i.e. the time resolved chromatography related to the evaluation of some important adsorption parameters.

Thus, a precise contribution to the elucidation of the mechanism of the deterioration of marbles, ceramics and titanium oxide pigments of various works of art in museums is achieved. These physicochemical quantities are: (1) local adsorption energy, (2) local monolayer capacity, (3) local adsorption isotherm, (4) density probability function, (5) nonadsorbed pollutant concentration on the solid surface, (6) energy for lateral interactions. All these adsorption parameters mentioned above have been calculated as a function of experimental time for the systems: $\mathrm{NO}_{2} / \mathrm{TiO}_{2}, \mathrm{NO}_{2} /$ Pentelic Marble, $\mathrm{NO}_{2} /$ Ceramic, $\mathrm{C}_{2} \mathrm{H}_{2} /$ $\mathrm{TiO}_{2}, \mathrm{C}_{2} \mathrm{H}_{2} /$ Pentelic Marble, $\mathrm{C}_{2} \mathrm{H}_{2} /$ Ceramic, as well as $\mathrm{C}_{2} \mathrm{H}_{2} / \mathrm{NO}_{2} / \mathrm{TiO}_{2}, \mathrm{C}_{2} \mathrm{H}_{2} / \mathrm{NO}_{2} /$ Pentelic Marble and $\mathrm{C}_{2} \mathrm{H}_{2} / \mathrm{NO}_{2} /$ Ceramic. This dynamic experimental technique leads also to very interesting experimental results, concerning the synergistic effects of the nitrogen oxide pollutant mentioned above.

Actually, a totally scientific answer will be given to the important question that arises from the presence of these pollutants and their contribution in artistic heritage deterioration.

\section{CALCULATIONS}

The synergistic effects between hydrocarbons and nitrogen dioxide lead to much greater damage and corrosion of these solids and perhaps of many others. The calculation of all the new physicochemical quantities has been performed using published models by Katsanos, $\mathrm{N}$. A. and Roubani-Kalantzopoulou, F. (Katsanos et al., 2000), which are available from the authors.

The main equation remains Eq.(1)

$H^{1 / M}=g c\left(I^{\prime}, t\right)=\sum_{i=1}^{4} A_{i} \exp \left(B_{i} t\right) s$

where: $\mathrm{H}$ : sample peak height resulting from the flow reversal, $\mathrm{cm}$.

$\mathrm{M}$ : response factor of the detector, dimensionless.

$\mathrm{g}$ : factor for the calibration of the detector, $\mathrm{cm} \mathrm{mol}^{-1} \mathrm{~cm}^{-3}$.

$c\left(l^{\prime}, t\right)$ : measured sampling concentration of the pollutant at $x=l^{\prime}, \mathrm{mol} \mathrm{cm}^{-3}$.

$A_{i}$ and $B_{i}$ are the pre-exponential factors and the exponential coefficients of time.

The local adsorption isotherm is given by

$\theta_{\mathrm{t}}=\frac{\mathrm{c}_{\mathrm{s}}^{*}}{\mathrm{c}_{\mathrm{smax}}^{*}}$

Where: $c_{s \max }^{*}$ is the local monolayer capacity, and $c_{s}{ }^{*}$ is the equilibrium adsorbed pollutant concentration

$\mathrm{c}_{\mathrm{smax}}^{*}=\mathrm{c}_{\mathrm{s}}^{*}+\frac{\partial \mathrm{c}_{\mathrm{s}}^{*} / \partial \mathrm{c}_{\mathrm{y}}}{\mathrm{KRT}}$

The relations for calculating the adsorption energy $\varepsilon\left(\mathrm{kJ} \mathrm{mol}^{-1}\right)$ and the modified probability density function $\varphi(\varepsilon)$ from experimental data are given by Eqs 4-6:

$$
\begin{aligned}
& \varepsilon=\mathrm{RT}\left[\ln (\mathrm{KRT})-\ln (\mathrm{RT})-\ln \mathrm{K}^{\mathrm{o}}\right] \\
& \varphi(\varepsilon ; \mathrm{t})=\frac{\theta \mathrm{f}(\varepsilon)}{\mathrm{C}_{\mathrm{smax}}^{*}} \\
& \text { where } \mathrm{f}(\varepsilon)=\frac{\partial \mathrm{c}_{\mathrm{s} \text { max }}^{*}}{\partial \varepsilon}=\frac{\partial \mathrm{c}_{\mathrm{s} \text { max }}^{*} / \partial \mathrm{t}}{\partial \varepsilon / \partial \mathrm{t}}
\end{aligned}
$$

The energy for the lateral interactions is given by Eq. 7:

$\beta=z \omega / R T$

where $\omega$ is the lateral interaction energy and $z$ the number of neighbors for each adsorption site. 


\section{EXPERIMENTAL}

Chromatographic measurements are carried out with a Shimadzu gas chromatograph, model $8 \mathrm{~A}$ with a FID or TCD detector. The experimental arrangement is analogous to that used in Refs (Roubani-Klantzopoulou et al., 2001; Kalantzopoulos et al., 1998; Agelakopoulou et al., 2007; Siokos et al., 2002). Here the section which is empty of any solid material has a length of $22.4 \mathrm{~cm}$, while that which contains the solid bed is $5.2 \mathrm{~cm}$. Both these sections are of pyrex glass of $3.5 \mathrm{~mm}$ ID. The sampling column, chromatographic tube of $4.0 \mathrm{~mm}$ ID, has total length $100 \mathrm{~cm}$ and is made of stainless steel.

The solid under examination is packed in the $5.2 \mathrm{~cm}$ solid bed. Before the adsorption experiments, this column with the adsorbent is conditioned at $473 \mathrm{~K}$ for $24 \mathrm{~h}$ under a flow of nitrogen, followed every time by the adjustment at the working temperature $(323.2 \mathrm{~K}$ or 353.2 $\mathrm{K})$. The flow-rate, which is measured at the outlet of the column, is $26.1 \mathrm{~cm}^{3} \mathrm{~min}^{-1}$. Ultra-highpurity nitrogen is used as carrier gas.

A small quantity of $1 \mathrm{~cm}^{3} \mathrm{C}_{2} \mathrm{H}_{2}$ and/or $\mathrm{NO}_{2}$ at atmospheric pressure is injected through the end of the diffusion column and after the appearance of the continuously rising concentration - time curve, the reversing procedure for the nitrogen carrier gas flow starts and is repeated every $2 \mathrm{~min}$. Each reversal lasts always $10 \mathrm{~s}$. The above procedure is performed automatically. The flow reversals create narrow, fairly symmetrical sample peaks, which are stored in a PC and finally printed.

\section{RESULTS}

On the basis of the above theoretical analysis, all the required adsorption parameters are determined using the experimental data (heights of chromatographic peaks in relation with time). The determined adsorption parameters are depicted versus time (cf. Figure 1).

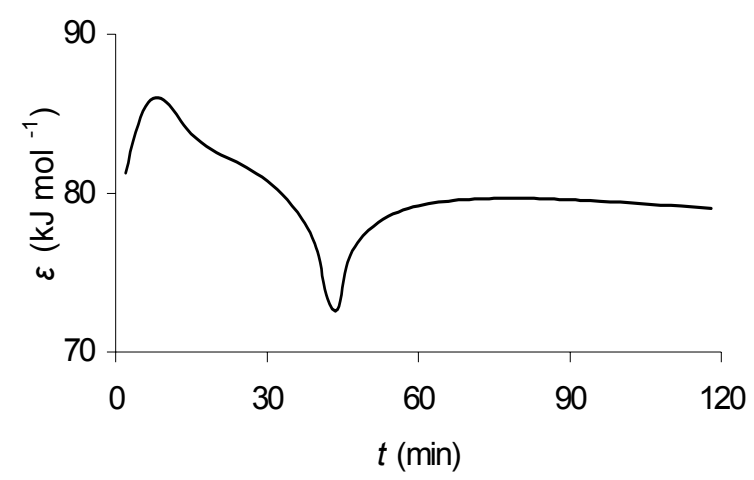

(a)

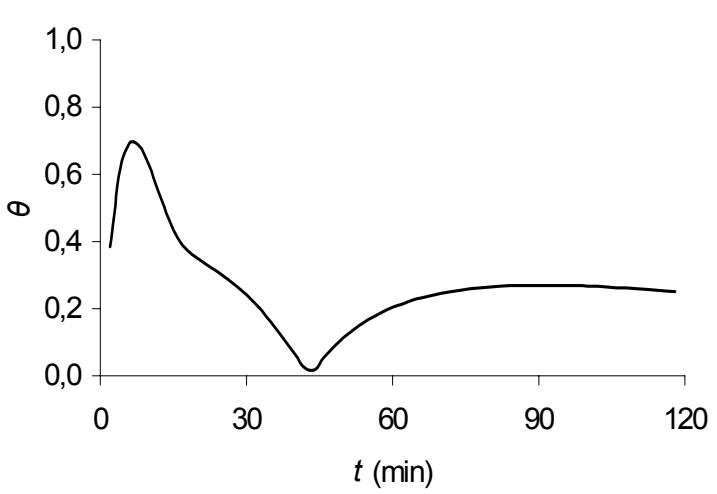

(b)

Figure 1. Plots of: (a) local adsorption energy, $\varepsilon$, (b) local adsorption isotherm, $\theta$, for the system: $\mathrm{NO}_{2} /$ Ceramic, at $323.2 \mathrm{~K}$.

Nitrogen dioxide is adsorbed from any kind of examined material, but in a different extent, corresponding to different adsorption parameters, as shown in the next Table 1, indicatively.

Table 1. Physicochemical adsorption quantities determined with the RF-IGC technique, concerning the influence of $\mathrm{NO}_{2}$ on $\mathrm{TiO}_{2}$ Pigment, Pentelic Marble and Ceramic.

\begin{tabular}{lccc}
\hline & $\mathrm{NO}_{\mathbf{2}} / \mathrm{TiO}_{\mathbf{2}}$ & $\begin{array}{c}\mathrm{NO}_{2} / \text { Pentelic } \\
\text { Marble }\end{array}$ & $\mathrm{NO}_{\mathbf{2}} /$ Ceramic \\
\hline$\varepsilon\left(\mathrm{kJ} \mathrm{mol}^{-1}\right)$ & $70-100$ & $73-91$ & $72-86$ \\
$\mathrm{c}^{*}{ }_{\text {smax }}\left(\mathrm{mol} \mathrm{g}^{-1}\right)$ & $1.8 \times 10^{-3}$ & 0.3 & $1.8 \times 10^{-3}$ \\
$\varphi(\varepsilon ; \mathrm{t})\left(\mathrm{mol} \mathrm{KJ}^{-1} \mathrm{~min}^{-1}\right)$ & $9.5 \times 10^{-2}$ & $9.5 \times 10^{-2}$ & $9.5 \times 10^{-2}$ \\
$\mathrm{c}_{\mathrm{y}}\left(\mathrm{mol} \mathrm{cm}^{-3}\right)$ & $2.5 \times 10^{-5}$ & $5.8 \times 10^{-6}$ & $5.3 \times 10^{-5}$ \\
\hline
\end{tabular}




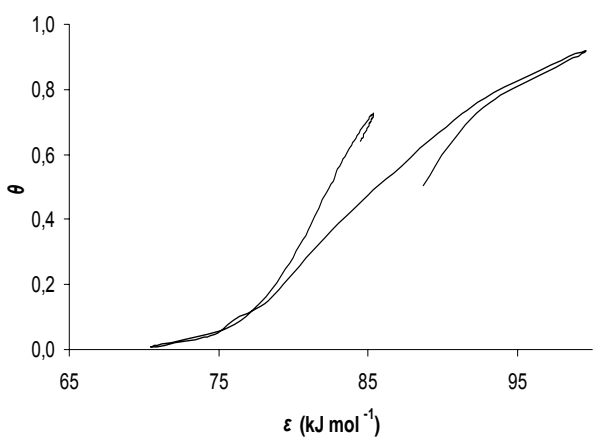

(a)

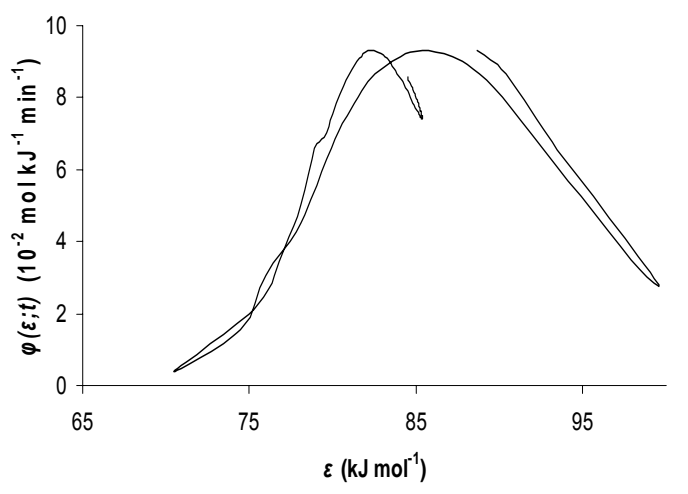

(b)

Figure 2. Plots of: (a) local adsorption isotherm, $\theta$, versus local adsorption energy, $\varepsilon$, (b) density probability function, $\varphi(\varepsilon ; t)$, versus local adsorption energy, $\varepsilon$, for the system

$\mathrm{NO}_{2} / \mathrm{TiO}_{2}$, at $323.2 \mathrm{~K}$.

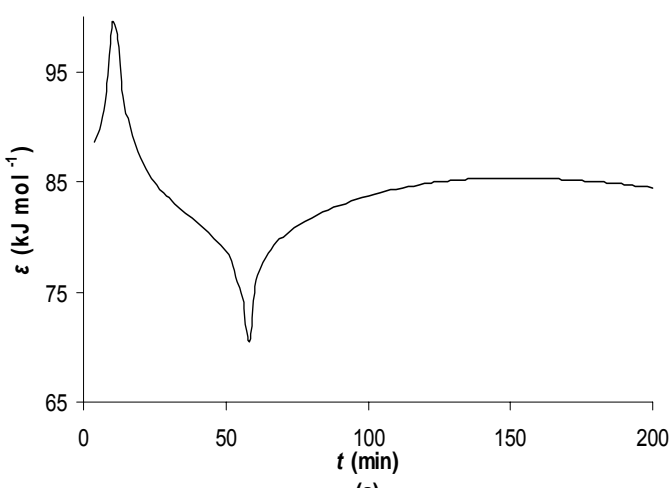

(a)

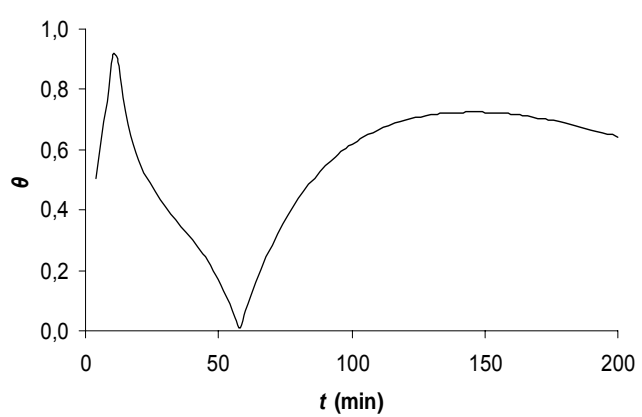

(c)

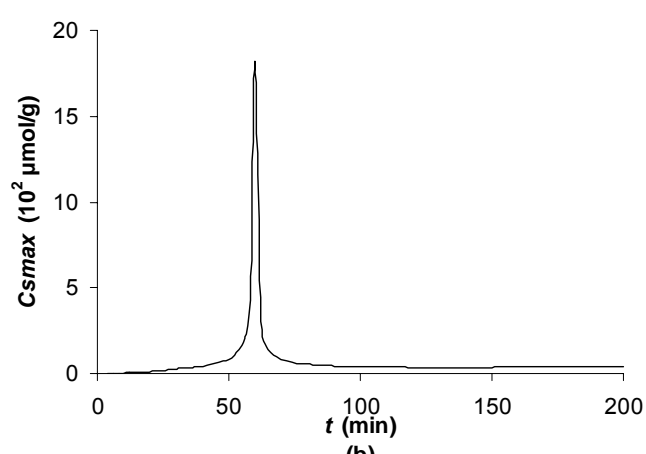

(b)

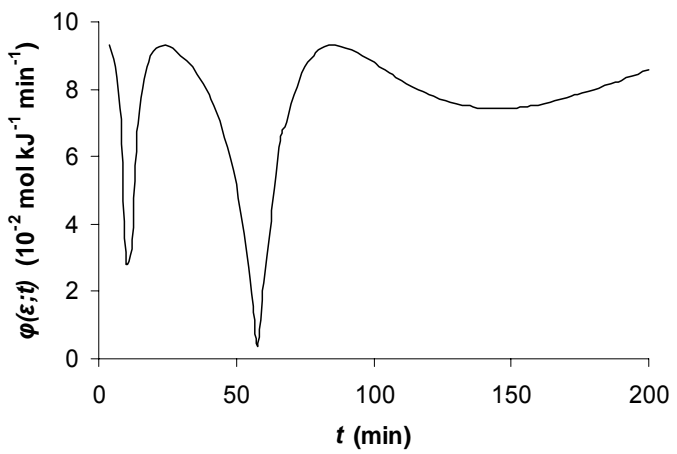

(d)

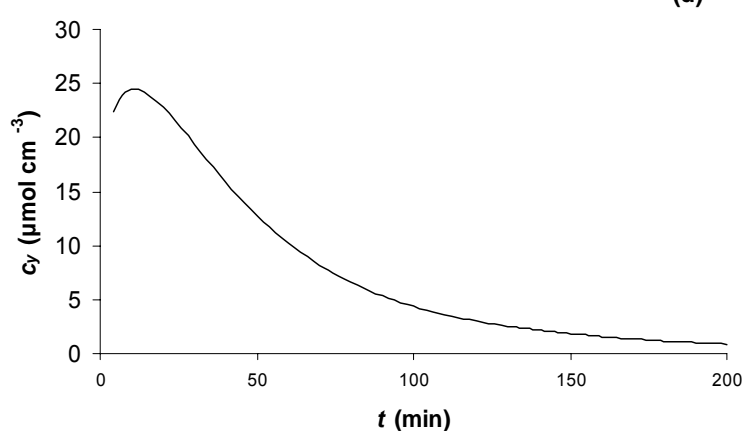

(e)

Figure 3. Plots of: (a) local adsorption energy, $\varepsilon$, (b) local monolayer capacity, $c^{*}{ }_{\text {smax }}$, (c) local adsorption isotherm, $\theta$, (d) density probability function, $\varphi(\varepsilon ; t),(e)$ concentration of the gaseous pollutant, $\mathrm{C}_{\mathrm{y}}$, versus $\mathrm{t}$ for the system: $\mathrm{NO}_{2} / \mathrm{TiO}_{2}$, at $323.2 \mathrm{~K}$. 
The experimental isotherm, as a function of adsorption energy (see Figure 2a), is thoroughly studied, as well as the Gauss distribution of adsorption energy function over all adsorption energies (see Figure $2 \mathrm{~b}$ ). These plots are indicative showing a behavior analogous to the results of Adamson (Adamson et al., 1996) for the first plot and of Gauss distribution for the second plot. Both of them are obtained experimentally.

The local monolayer capacity either for the system $\mathrm{NO}_{2} / \mathrm{TiO}_{2}$ or for the $\mathrm{NO}_{2} /$ ceramic sample (cf. Table 1), corresponding to the same experimental time, is the same. However, it is higher in the case of marble, which is attributed to the structure of the material.

As regards the system $\mathrm{C}_{2} \mathrm{H}_{2}$ / Pentelic Marble, the time resolved analysis leads to the calculation of local adsorption energy, local adsorption isotherm, density probability function, pollutant concentration on marble at any experimental time. The same local adsorption parameters, concerning the system $\mathrm{C}_{2} \mathrm{H}_{2} / \mathrm{NO}_{2}$ / Pentelic Marble are determined, studied and compared. It seems that the range of local adsorption energy $\varepsilon$ corresponds to smaller values in the presence of $\mathrm{NO}_{2}$ (see Figures 4a, 5a). Thus, again it is shown that $\mathrm{NO}_{2}$ (Siokos et al., 2002) modifies the adsorption of $\mathrm{C}_{2} \mathrm{H}_{2}$, which now takes place at lower adsorption energies.

As far as the local monolayer capacity is concerned, corresponding to the same experimental time, it appears lower in the presence of $\mathrm{NO}_{2}$ (see Figures $4 b, 5 b$ ), in spite of the fact that maintains the same order. This fact coincides with the previous result.

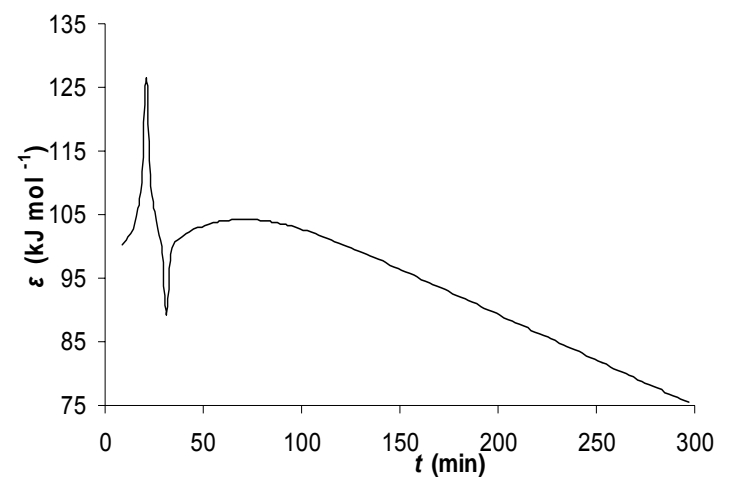

(a)

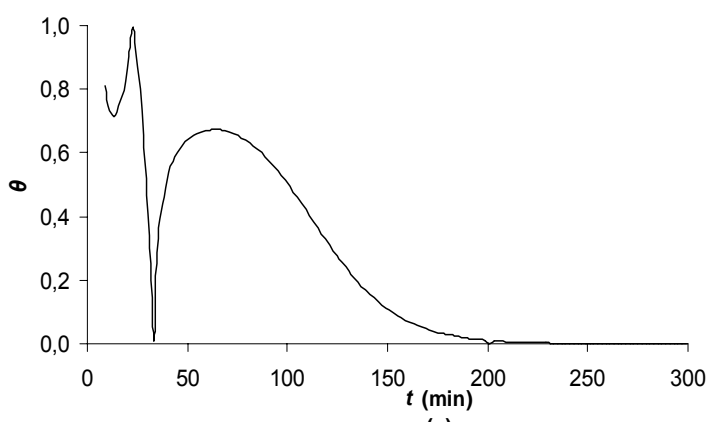

(c)

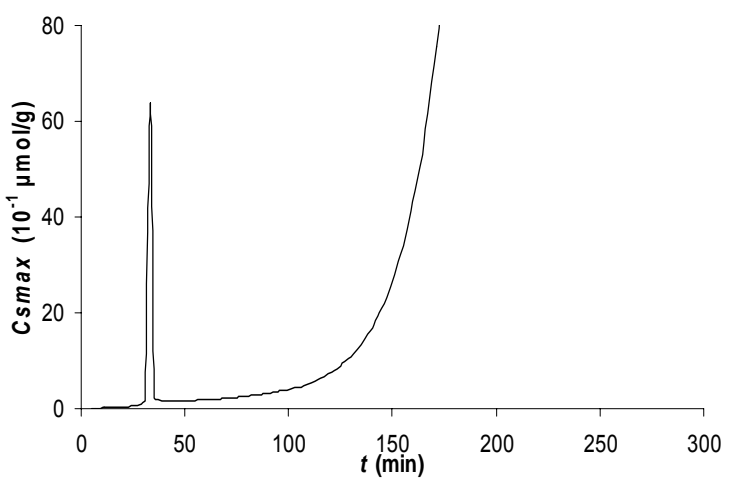

(b)

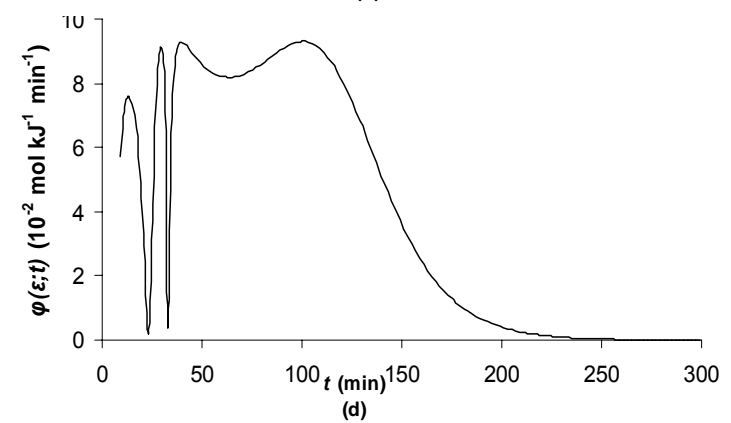

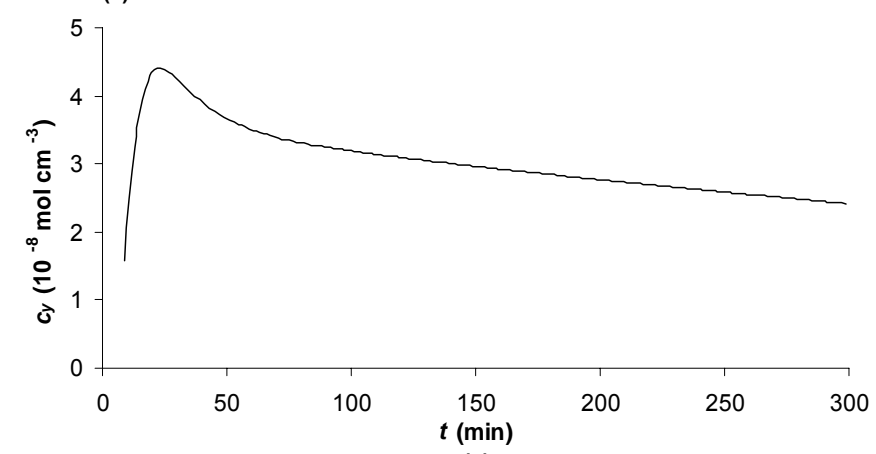

(e)

Figure 4. Plots of: (a) local adsorption energy, $\varepsilon$, (b) local monolayer capacity, $c^{*}$ smax, (c) local adsorption isotherm, $\theta$, (d) density probability function, $\varphi(\varepsilon ; t),(e)$ concentration of the gaseous pollutant, $\mathrm{C}_{y}$, for the system: $\mathrm{C}_{2} \mathrm{H}_{2}$ / Pentelic Marble, at $323.2 \mathrm{~K}$. 
The value of the density probability function depends directly on the experimental temperature (Metaxa et al., 2007). So, it appears the same for both the systems $\mathrm{C}_{2} \mathrm{H}_{2}$ / Pentelic Marble and $\mathrm{C}_{2} \mathrm{H}_{2} / \mathrm{NO}_{2} /$ Pentelic Marble, at the same temperature (cf. Figures $4 \mathrm{~d}, 5 \mathrm{~d}$ ). It is also noticed from the time-resolved analysis of $\varphi(\varepsilon ; t)$ (cf. Figures $3 \mathrm{~d}, 4 \mathrm{~d}, 5 \mathrm{~d}$ ), that three kinds of adsorption active centers appear separately, as in other cases (Katsanos et al., 1999). From these three maxima, the first one is attributed to chemisorption with a random distribution of the active sites and the other two to Van der Waals forces, with a patchwise topography.

The maximum value of the local adsorption isotherm diminishes with the increase of the temperature as well as with the experimental time needed. As far as $c_{y}$ is concerned, it takes higher value in the presence of $\mathrm{NO}_{2}$ (cf. Figures $4 \mathrm{e}, 5 \mathrm{e}$ ). That is, $\mathrm{NO}_{2}$ molecules occupy the first active sites of the surface and the hydrocarbon the remaining ones.

In general, through all figures it can be observed that the shape of the curves remains unchanged, regarding the same physicochemical quantity. This concludes to a standard behavior for these quantities. It is the times of maxima and minima that change for each system. A general also observation is that in the presence of $\mathrm{NO}_{2}$ these times are lower.

Moreover, the study of the pollution impact on the solids studied, is very detail and accurate. At the same time, the surface topography and the mechanism of deterioration is also achieved.

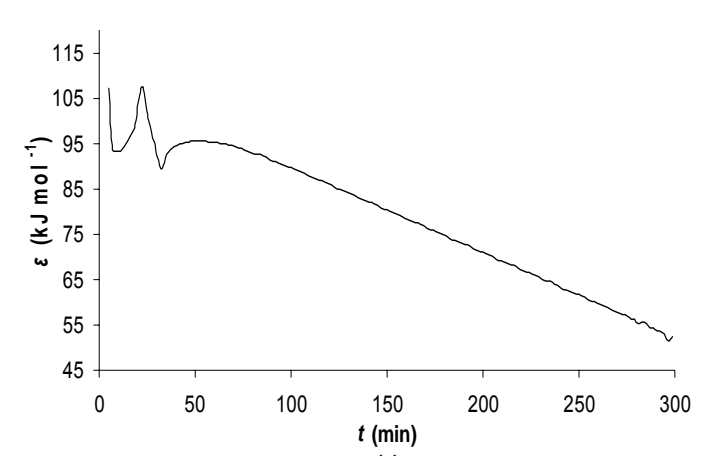

(a)

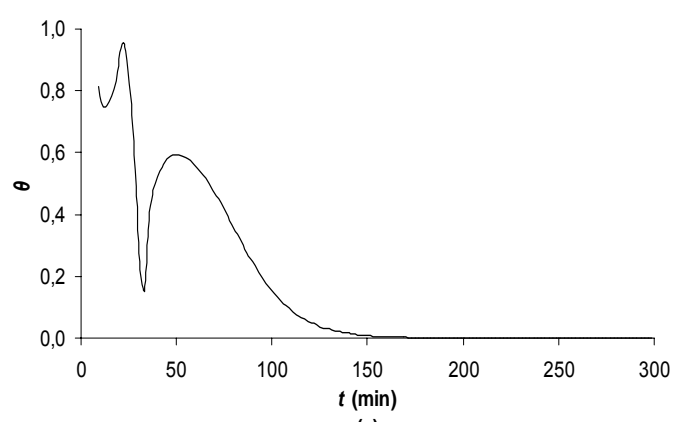

(c)

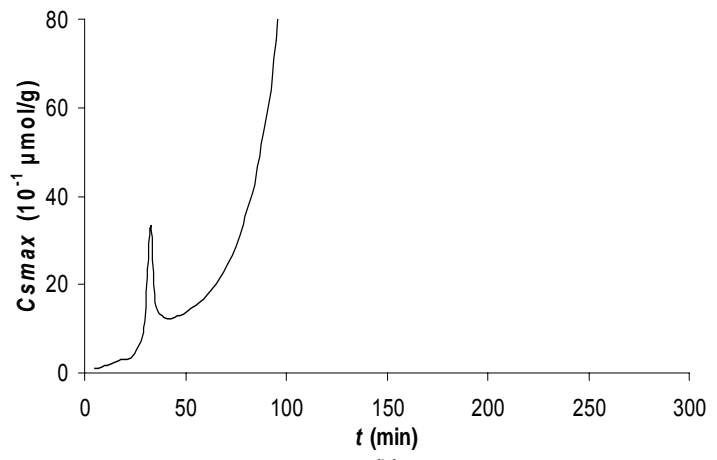

(b)

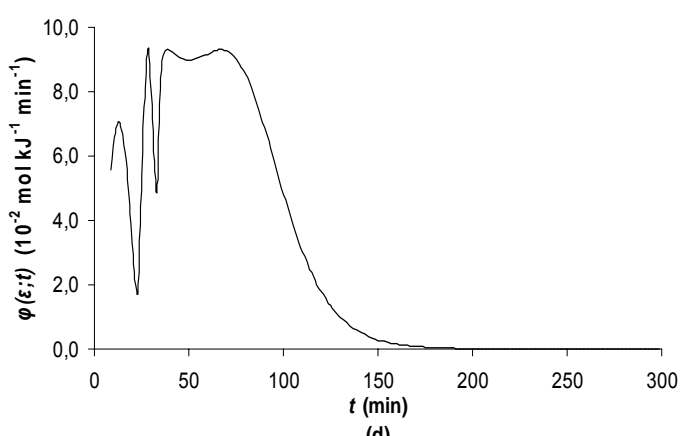

(d)

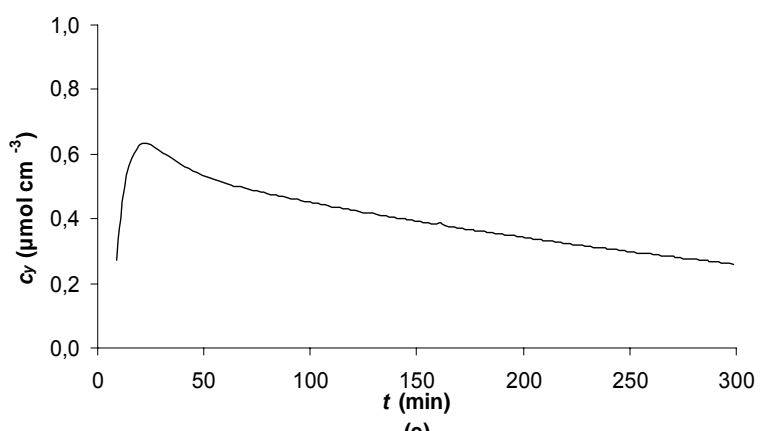

(e)

Figure 5. Plots of: (a) local adsorption energy, $\varepsilon$, (b) local monolayer capacity, $c^{*}{ }_{\text {smax }}$, (c) local adsorption isotherm, $\theta$, (d) density probability function, $\varphi(\varepsilon ; t),(e)$ concentration of the gaseous pollutant, $\mathrm{C}_{\mathrm{y}}$, for the system: $\mathrm{C}_{2} \mathrm{H}_{2} / \mathrm{NO}_{2} /$ Pentelic Marble, at $323.2 \mathrm{~K}$. 
Thus, in order to achieve a better understanding in the adsorption of the pollutants, further analysis was performed (cf. Figures 6-8).

From the plots of density probability function, $\varphi(\varepsilon ; t)$, versus energy for lateral interactions, $\beta$, it is shown that only two distinct regions appear (not three as in plots of $\varphi(\varepsilon ; t)$ against $t$ ), which are attributed to the attractive interactions between the molecules of the adsorbate. The first region is attributed to the attractive interactions of neighboring molecules, which have already been adsorbed, the second region corresponds to the attractive forces between molecules which exist far away. So, it is easy the percentage of the respective adsorbed molecules to be determined.

The variation of local adsorption isotherm, $\theta$, versus the energy for lateral interactions, $\beta$, is studied. The high values of $\theta$ correspond to chemisorption of the adsorbed gas, the lower ones to physisorption due to Van der Waals forces. It is noticed a gradual decrease of $\theta$ until one minimum value, with simultaneous increase of $\beta$. A decrease of the attractive forces between adsorbent and adsorbate and a parallel increase of the respective forces between adsorbate-adsorbate molecules is observed. (cf. Figures $6 b, 7 b, 8 b$ ).

As regards the variation of $\varepsilon$ with $\beta$, it is noticed that as the chemisorption is decreasing, more and more Van-der Waals forces appear (cf. Figures 6a, 7a, 8a). The negative values of $\beta$ denotes chemisorption.

The minima in the plots of $\varepsilon-\beta, \theta-\beta, \varphi(\varepsilon ; t)-\beta$ occur in the same value of $\beta$ for each system.

The two maxima of the plot of $\varphi(\varepsilon ; t)$ versus $\beta$ (for positive values of $\beta$ ) correspond to the second and third maxima of the curves of $\varphi(\varepsilon ; t)$ versus $t$, which have been attributed to physisorption (cf. Figures 6c, 7c, 8c).

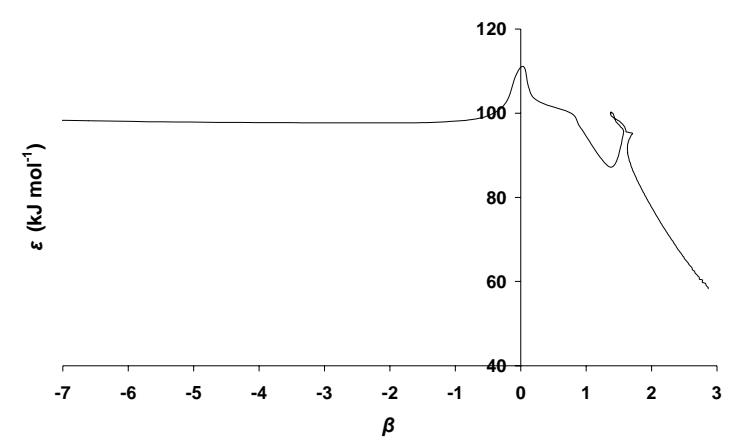

(a)

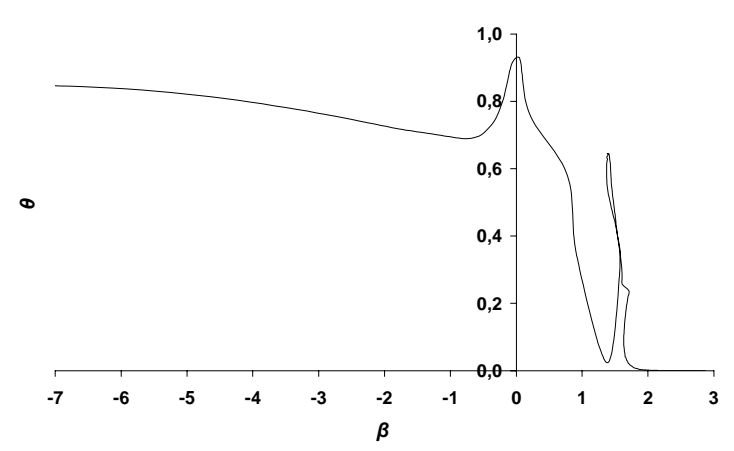

(b)

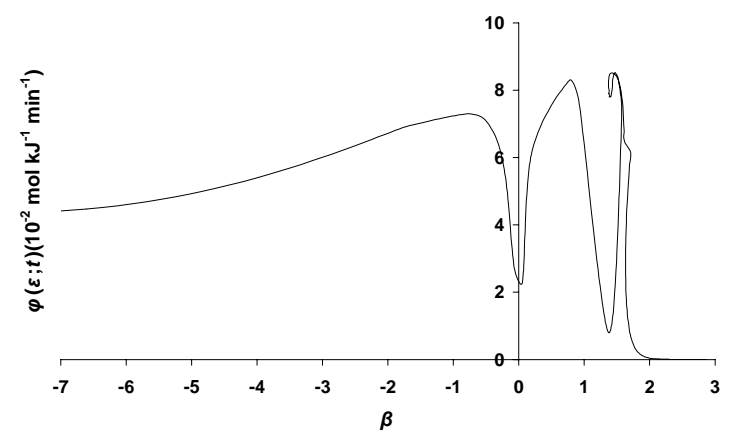

(c)

Figure 6. Plots of: (a) local adsorption energy, $\varepsilon$, (b) local adsorption isotherm, $\theta$, (c) density probability function, $\varphi(\varepsilon ; t)$, versus energy for lateral interactions, $\beta$, for the system: $\mathrm{C}_{2} \mathrm{H}_{2} / \mathrm{NO}_{2} /$ Pentelic Marble, at $353.2 \mathrm{~K}$. 


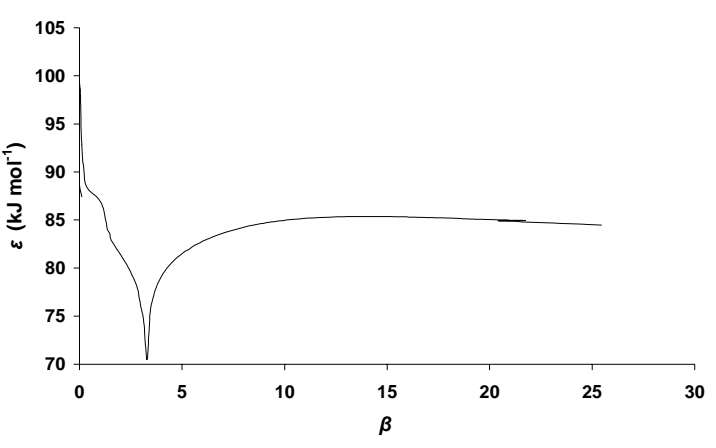

(a)

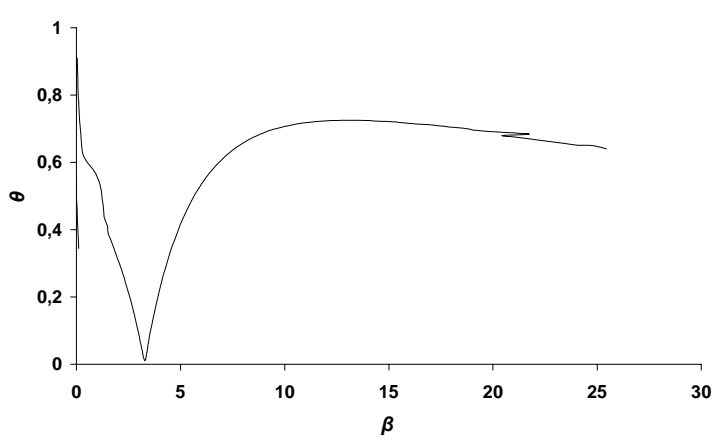

(b)

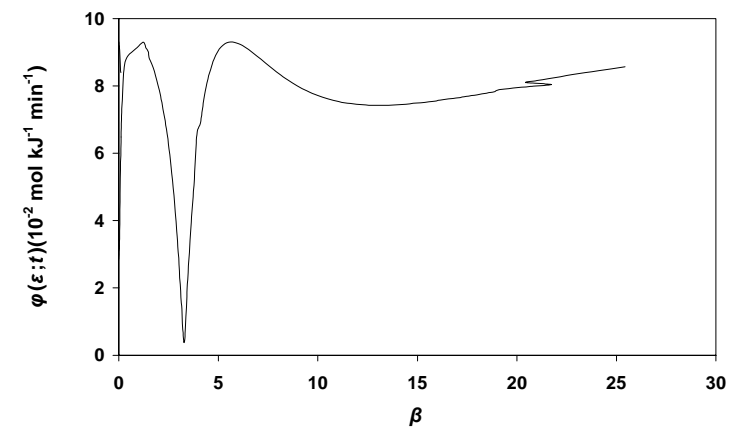

(c)

Figure 7. Plots of: (a) local adsorption energy, $\varepsilon$, (b) local adsorption isotherm, $\theta$, (c) density probability function, $\varphi(\varepsilon ; t)$, versus energy for lateral interactions, $\beta$, for the system: $\mathrm{NO}_{2} / \mathrm{TiO}_{2}$, at $323.2 \mathrm{~K}$.

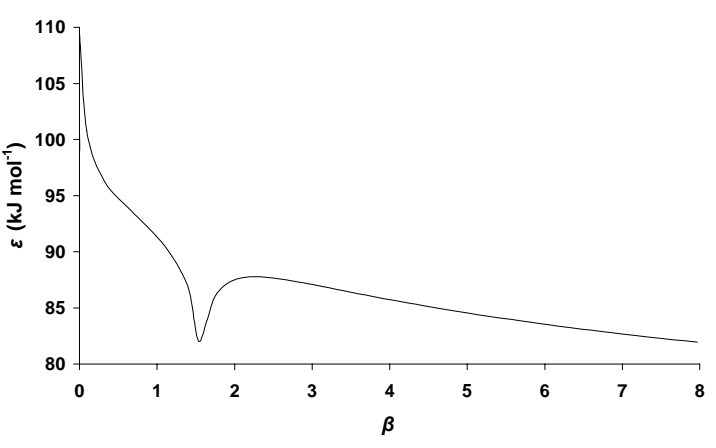

(a)

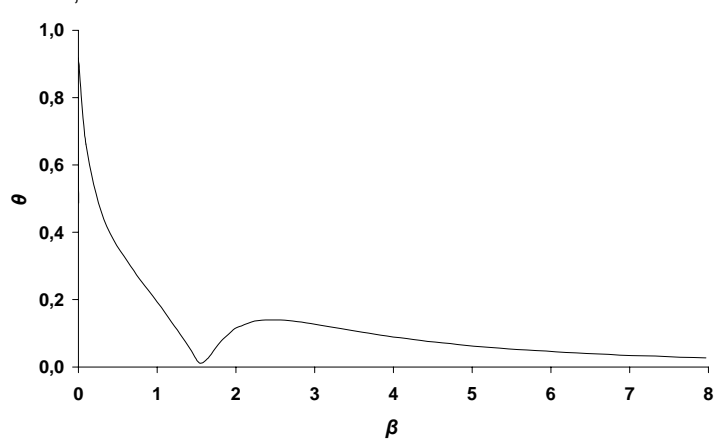

(b)

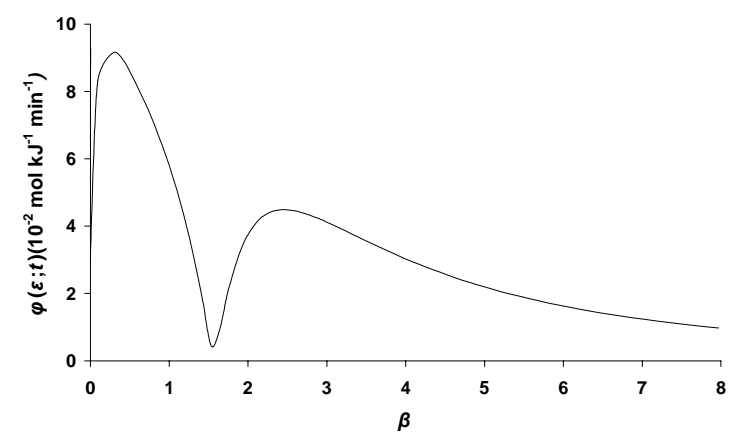

(c)

Figure 8. Plots of: (a) local adsorption energy, $\varepsilon$, (b) local adsorption isotherm, $\theta$, (c) density probability function, $\varphi(\varepsilon ; t)$, versus energy for lateral interactions, $\beta$, for the system: $\mathrm{NO}_{2} /$ ceramic, at $323.2 \mathrm{~K}$.

It is obvious that differences in the behavior of the three solids against the same pollutants exist. By our opinion, it is the structure of the solids and pollutants that is responsible for these differences. Thus, the research must be continued towards this direction. 


\section{ACKNOWLEDGMENTS}

The Project is co-funded by the European Social Fund (75\%) and National Resources (25\%) (EPEAEK II)- PYTHAGORAS.

\section{REFERENCES}

Adamson W.A. (1996), Physical adsorption of vapors - three personae, Colloids and Surfaces A, 118, 193-201.

Agelakopoulou T., Bassiotis I., Margariti S., Metaxa E., Siokos V., Roubani-Kalantzopoulou F. (2007), Benzene and toluene influence with or without nitrogen dioxide on inorganic pigments of works of art - Part II, Atmospheric Environment, 41, 2009-2018.

Arvanitopoulou E., Katsanos N.A., Metaxa E., Roubani-Kalantzopoulou F. (1994), I. Simple measurement of deposition velocities and wall reaction probabilities in denuder tubes. II. High deposition velocities, Atmospheric Environment, 28, 10, 1791-1802.

Charmas B., Leboda R. (2000), Effect of surface heterogeneity on adsorption on solid surfaces: Application of inverse gas chromatography in the studies of energetic heterogeneity of adsorbents, Journal of Chromatography A, 886, 133-152.

Eiceman A.G., Hill Jr.H., Gardea-Torresdey J. (2000), Gas chromatography, Analytical Chemistry, 72, 12, 137R-144R.

Kalantzopoulos A., Birbatakou S., Roubani-Kalantzopoulou F. (1998), Benzene and toluene influence with or without nitrogen dioxide on inorganic pigments of works of art, Atmospheric Environment, 32, 1811-1816.

Katsanos N.A., Iliopoulou E., Roubani-Kalantzopoulou F., Kalogirou E. (1999), Probability Density Function for Adsorption Energies over Time on Heterogeneous Surfaces by Inverse Gas Chromatography, Journal of Physical Chemistry B, 103, 10228-10233.

Katsanos N.A., Roubani-Kalantzopoulou F. (2000), Advances in Chromatography, Advances in Chromatography, 40, 231-245.

Metallo-Chiara M., Poli A., Diana M., Persia F., Cirillo M. (1995), Pollution loads on historical monuments - an air quality model application to the marble arch of Titus in Rome, Science of Total Environment, 172, 163-172.

Metaxa E., Agelakopoulou T., Bassiotis I., Margariti S., Siokos V., Roubani-Kalantzopoulou F. (2007), Time - Resolved Gas Chromatography Applied to Submonolayer Adsorption Modeling and Experimental Approach, Applied Surface Science, 253, 5841-5845.

Roubani-Kalantzopoulou F. (2004), Determination of isotherms by gas - solid chromatography, Applications. Journal of Chromatography A, 1037, 191-221.

Roubani - Kalantzopoulou F., Bassiotis I., Artemiadi Th., Margariti S., Arvanitopoulou E., Katsanos N.A. (2001), Simulation of the Physicochemical Processes in the Atmosphere, Fresenius Environmental Bulletin, 10, 1, 98-102.

Siokos V., Kapolos J., Roubani-Kalantzopoulou F. (2002), Physicochemical characterization of inorganic pigments in the presence of gaseous pollutants. The role of ozone, Zeitschrift für Physikalische Chemie, 216, 1311-1321. 